\title{
To study and compare the obstetric and neonatal outcome of pregnancies complicated with hypothyroidism amongst antenatally detected and treated hypothyroid patients and patients found to be hypothyroid at the time of labor
}

\author{
Parmanand K. Shah, Hemangi K. Chaudhari*, Delina A. Mathias
}

Department of Obstetrics and Gynaecology, Seth G. S. Medical College and K.E.M. Hospital, Mumbai, India

Received: 04 June 2016

Accepted: 11 June 2016

\author{
*Correspondence: \\ Dr. Hemangi Kashinath Chaudhari, \\ E-mail: hemangichaudharik@gmail.com
}

Copyright: () the author(s), publisher and licensee Medip Academy. This is an open-access article distributed under the terms of the Creative Commons Attribution Non-Commercial License, which permits unrestricted non-commercial use, distribution, and reproduction in any medium, provided the original work is properly cited.

\begin{abstract}
Background: To evaluate pregnancy outcome in women with elevated serum thyroid stimulating hormone (TSH) values as compared to those in whom hypothyroidism was treated.

Methods: A prospective interventional comparative study was conducted in the department of obstetrics and gynaecology in King Edward Memorial Hospital, Mumbai, India from 2014 to 2015. A cohort of 60 hypothyroid patients was divided into two groups of 30 each. Group 1, euthyroid (treated hypothyroid) and group 2, hypothyroid at the time of labor and pregnancy outcomes were compared.

Results: All patients in group 1 delivered at term; whereas in group 2, 9 (30\%) patients had preterm deliveries and 21 $(70 \%)$ delivered at term, amongst which 5 patients delivered babies with severe intrauterine growth restriction (IUGR). Neonatal intensive-care unit (NICU) admission were required for 3 neonates in group 1 and $11(36.67 \%)$ neonates in group 2. Group 1 delivered 5 (16.67\%) low birth weight babies (weight $<2.5 \mathrm{~kg}$ ) whereas $16(53.34 \%)$ babies had low birth weight in group 2.

Conclusions: Treatment of patients diagnosed with hypothyroidism during pregnancy significantly $(\mathrm{p}$ value $<0.05)$ reduced the risk of preterm labor, low birth weight, need for NICU admission.
\end{abstract}

Keywords: Hypothyroidism, Pregnancy, Obstetric outcome, Neonatal outcome, Cohort study

\section{INTRODUCTION}

Thyroid diseases are common worldwide. Prevalence and incidence of thyroid disorders in pregnancy as per western literature is around $2.5 \% .^{1}$ Recent publication from department of endocrinology of King Edward Memorial (KEM) Hospital, Mumbai, India showed thyroid dysfunction in Indian pregnant women to be $4.8 \%$ in first trimester. ${ }^{2}$ Data on the impact and incidence of thyroid disorders during pregnancy in Indian population is lacking.

Maternal hypothyroidism is a disorder with great potential to adversely affect maternal and fetal outcomes.
While overt hypothyroidism causes infertility and amenorrhea, it is the borderline or the subclinical and inadequately treated hypothyroid patients who present with pregnancy complications such as hypertension, placental abruption, postpartum haemorrhage, preterm birth, anaemia low birth weight, intrauterine growth restriction and intrauterine fetal demise. ${ }^{3}$

If the condition is detected early, it is easy to treat, with very little detriment to the mother and the fetus. Therefore this study is planned to establish thyroid dysfunction, note its effect on pregnancy with treatment and to evaluate maternal and neonatal outcome. 


\section{METHODS}

The study was approved by ethics committee of Seth G. S. Medical College, Mumbai, India. All ANC patients registered in KEM Hospital were subjected to TSH values at their first visit. All patients with high serum $\mathrm{TSH}(>2.5 \mu \mathrm{IU} / \mathrm{ml}$ in first trimester and $>3 \mu \mathrm{IU} / \mathrm{ml}$ in second and third trimester) found to be hypothyroid received treatment and were followed up 4 weekly with serum TSH levels till they reached euthyroid state.

Group 1 included patients who were diagnosed to be hypothyroid for the first time during pregnancy irrespective of the period of gestation and not in labor and ones diagnosed preconceptionally who remained hypothyroid when pregnant. All such patients were treated and a repeat TSH was sent at the time of labor to check for their euthyroid status.

Group 2 included all unregistered patients, referred patients who have not undergone study for thyroid disorders during pregnancy and those who were found to be hypothyroid at the time of delivery despite treatment due to noncompliance.

Serum TSH of the neonates were sent routinely on the third day postpartum by the neonatologist to check for their thyroid status.

\section{Inclusion criteria}

- All pregnant hypothyroid patients were included irrespective of registration status, parity index and gestational age.

- Women attending antenatal services either on OPD basis or through emergency basis.

- Patients who were referred to the institution only at the time of delivery.

\section{Exclusion criteria}

- Patients with any other medical illness were excluded from the study.

- Preconceptionally diagnosed and treated patients who are euthyroid during pregnancy.

- Patients registered in the study but delivered elsewhere were withdrawn from the study.

A comparative study therefore was obtained between the two groups based on the following parameters:

Maternal outcomes like preterm labor, oligohydramnios, pregnancy induced hypertension, antepartum haemorrhage (placental abruption), anaemia.

Neonatal outcomes like preterm birth, low birth weight, intrauterine growth restriction, hypothyroidism, hyperbilirubinaemia, APGAR score, meconium aspiration, respiratory distress, need for NICU admission and neonatal death.

\section{RESULTS}

In our study, all 30 patients in group 1 were delivered at term whereas in group 2, $9(30 \%)$ patients had preterm deliveries and 21 (70\%) delivered at term, amongst which 5 patients delivered babies with severe IUGR.

Table 1: Comparison of birth weight among study groups.

\begin{tabular}{|lll|l|}
\hline $\begin{array}{l}\text { Birth } \\
\text { weight in } \\
\text { kg. }\end{array}$ & $\begin{array}{l}\text { Thyroid status } \\
\text { Euthyroid }\end{array}$ & Hypothyroid & \\
\hline$<1.5$ & $0.0 \%$ & $6.7 \%$ & $3.3 \%$ \\
\hline 1.5 to 1.99 & $0.0 \%$ & $30.0 \%$ & $15.0 \%$ \\
\hline 2 to 2.49 & $16.7 \%$ & $12.7 \%$ & $16.7 \%$ \\
\hline 2.5 to 2.99 & $46.7 \%$ & $33.3 \%$ & $40.0 \%$ \\
\hline 3 to 3.49 & $33.3 \%$ & $10.0 \%$ & $21.7 \%$ \\
\hline 3.5 to 3.99 & $3.3 \%$ & $3.3 \%$ & $3.3 \%$ \\
\hline Total & $100.0 \%$ & $100.0 \%$ & $100.0 \%$ \\
\hline $\begin{array}{l}\text { Chi-square } \\
\text { test }\end{array}$ & $\mathrm{df}=5$ & $\begin{array}{l}\text { P-value is } \\
0.009\end{array}$ & $\begin{array}{l}\text { Significant } \\
\text { association }\end{array}$ \\
\hline
\end{tabular}

NICU admission were required for 3 neonates in group 1 and $11(36.67 \%)$ neonates in group 2 .

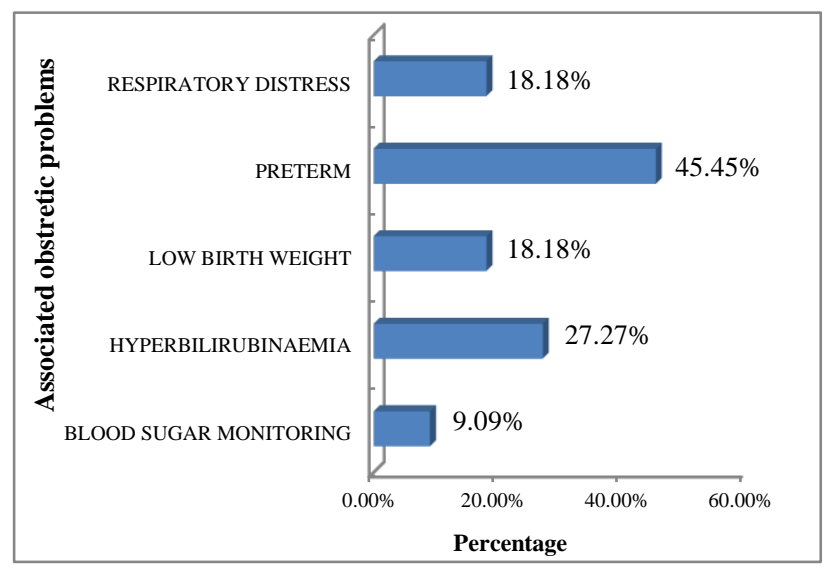

Figure 1: Distribution of reason for NICU admission among hypothyroid group.

A comparable yet not statistically significant difference was obtained based on co-morbidities like anaemia, postpartum haemorrhage, oligohydramnios, pregnancy induced hypertension and abruption with morbidities being more common in group. ${ }^{2}$

\section{DISCUSSION}

This study shows significant difference $(\mathrm{p}$ value $<0.05$ ) in pregnancy outcome amongst treated hypothyroid patients in terms of gestational weeks at delivery, birth weight, need for NICU stay with morbidities being more common 
in the hypothyroid group. Larger studies though are needed to bring out the significance amongst other associated obstetric outcomes, this study certainly shows comparative results with lower incidence amongst euthyroid group.

In the study by Casey et al, women with subclinical hypothyroidism had a significant almost 2 fold higher incidence of preterm delivery and admission to NICU were twice as likely in infants delivered of women with subclinical hypothyroidism as compared to the control group of normal healthy pregnant women. ${ }^{1}$

Study by Abalovich et al, showed that the evolution of pregnancies did not depend on whether the hypothyroidism was overt or subclinical but mainly on the treatment received. ${ }^{5}$ In their study, fifty one pregnancies were conceived under hypothyroidism: 16 overt and 35 subclinical hypothyroidism; 99 pregnancies were conceived under euthyroidism while undergoing thyroid therapy. When treatment with levothyroxine was inadequate, the outcome in pregnancy were abortion in $60 \%$ of overtly hypothyroid patients and in $71.4 \%$ of subclinically hypothyroid patients, premature delivery in $20 \%$ and $7.2 \%$ respectively, and term delivery in $20 \%$ and $21.4 \%$ respectively. When treated, $100 \%$ of overtly hypothyroid patients and $90.5 \%$ of sub clinically hypothyroid patients carried pregnancies to term; there were no abortions in any of the groups.
In a study by Sahu et al at AIIMS, Delhi, complications like hypertensive disorders of pregnancy $(9.8 \%)$, preterm labor $(10.3 \%)$, IUGR $(2.4 \%)$, were seen in cases of subclinical hypothyroidism. In the same study, hypertensive disorders of pregnancy $(20.7 \%)$ and IUGR $(13.8 \%)$, still birth $(2.9 \%)$ were seen in cases of overt hypothyroidism. ${ }^{6}$ In the study by Masanao et al, $18.26 \%$ of babies born to patients with hypothyroidism had IUGR, 22.22\% patients had hypertension, $7.69 \%$ had IUFD, $6.67 \%$ had abruption and $18.26 \%$ had diabetes. ${ }^{7}$ It has been noted that hypothyroidism in pregnant women can unfavorably affect the children's subsequent psychoneurotic development. ${ }^{8}$ Untreated maternal overt hypothyroidism is connected with adverse neonatal outcomes including premature birth, low birth weight, and neonatal respiratory distress. ${ }^{9}$ Complications in the pregnancies associated with hypothyroidism are complex and serious, with an important increase of the maternal morbidity, and perinatal morbidity and mortality. ${ }^{10}$ Targeted thyroid function testing of only the high-risk group would miss about one third of pregnant women with overt/subclinical hypothyroidism. ${ }^{11}$ This condition needs early detection, prompt initiation of treatment, adequate follow-up and most importantly, sufficient education of the doctors and the patients regarding these objectives, the importance of this condition and the ease and advantages of prompt management. ${ }^{12}$

Table 2: Incidence of complications in hypothyroidism.

\begin{tabular}{|c|c|c|c|c|c|c|}
\hline Study & $\begin{array}{l}\text { Hypertensive disorder } \\
\text { of pregnancy }\end{array}$ & $\begin{array}{l}\text { Gestational } \\
\text { diabetes mellitus }\end{array}$ & IUGR & Abruption & Preterm labour & Still birth \\
\hline Present & $13.33 \%$ & $6.67 \%$ & $16.67 \%$ & $6.67 \%$ & $30 \%$ & 16.67 \\
\hline \multirow{2}{*}{ Sahu MT ${ }^{5}$} & Subclinical 9.8\% & & $2.4 \%$ & & $10.3 \%$ & \\
\hline & Overt $20.7 \%$ & & $13.8 \%$ & & & $2.9 \%$ \\
\hline Masanao $^{6}$ & $22.22 \%$ & $18.26 \%$ & $18.26 \%$ & $6.67 \%$ & & $7.69 \%$ \\
\hline
\end{tabular}

\section{CONCLUSION}

Based on the result of the present study, in light of the increased prevalence of hypothyroidism, the adverse outcome associated and the ease and potential benefit of treatment of the condition, it may be recommended that universal screening for thyroid dysfunction in pregnancy is necessary.

\section{Clinical significance}

Treatment of patients diagnosed with hypothyroidism during pregnancy significantly reduced the risk of preterm labour, low birth weight, need for NICU admission.
Funding: No funding sources Conflict of interest: None declared

Ethical approval: The study was approved by the Institutional Ethics Committee

\section{REFERENCES}

1. Lebeau SO, Mandel SJ. Thyroid disorders during pregnancy. Endocrin Meta Clin North Am. 2006;35(1):117-36.

2. Nambiar V, Jagtap V, Shah N. Prevalence and impact of thyroid disorders on maternal outcome in Asian-Indian pregnant woman. J Thyroid Research. 2011;90(2):489-95.

3. Toth B, Jeschke U, Rogenhofer N, Scholz C, Würfel W, Thaler CJ. Recurrent miscarriage: current concept 
in diagnosis and treatment. J Reprod Immunology. 2010;8:25-32.

4. Casey BM, Dashe JS, Well CE. Subclinical hypothyroidism and pregnancy outcomes. Obstet Gynecol. 2005;10(5):239-45.

5. Sahu MT, Das V, Mittal S, Agarwal A, Sahu M. Overt and subclinical thyroid dysfunction among Indian pregnant women and its effect on maternal and fetal outcome. Arch Gyne Obst. 2010;281(2):215-20.

6. Ohashi M, Furukawa S, Michikata K, Kai K, Sameshima H. Risk-based screening for thyroid dysfunction during pregnancy. J Pregnancy. 2013;619718:1-5.

7. Gaberscek S, Zaletel K. Thyroid physiology and autoimmunity in pregnancy and after delivery. Expert Rev Clin Immunol. 2011;7(5):697-707.
8. Kurioka H, Takahasshi K, Miyazaki K. Maternal thyroid function during pregnancy and puerperal period. Endocr J. 2005;52(5):587-91.

9. Gwiezdzinska JK, Burman KD. Levothyroxine treatment in pregnancy: indications, efficacy and therapeutic regimen. J Thyro Res. 2011;84349:1-12.

10. Tudosa R, Vartej P, Horhoianu I, Ghica C, Mateescu $\mathrm{S}$, Dumitrache I. Maternal and fetal complications of the hypothyroidism related pregnancy. J Clinic Med. 2010;5(2):116-23.

11. Vaidya B, Antony S, Shields B, Drury J, Hutchison S. Detection of thyroid dysfunction in early pregnancy universal screening or high risk targeted case finding? J Clin Endocronol Metab. 2007;92(1):203-7.

12. Negro R, Alan Schwartz. Detection and treatment of thyroid in pregnancy. J Clin Endocrinol Metab. 2010;95(4):1699-707.

Cite this article as: Shah $\mathrm{PK}$, Chaudhari $\mathrm{HK}$, Mathias DA. To study and compare the obstetric and neonatal outcome of pregnancies complicated with hypothyroidism amongst antenatally detected and treated hypothyroid patients and patients found to be hypothyroid at the time of labor. Int J Reprod Contracept Obstet Gynecol 2016;5:2097-100. 